\title{
Adaptive Under-Frequency Load Shedding Scheme for Islanded Distribution Network based on Swing Equation
}

\author{
Nauman Ahmed ${ }^{1}$, Dr. Muhammad Naeem Arbab ${ }^{2}$, Hammad Israil Awan ${ }^{3}$, Shehla Noor ${ }^{4}$ \\ ${ }^{1,3,4}$ PG Research student, Dept. of EEE, University of Engineering and technology Peshawar, KP, Pakistan \\ ${ }^{2}$ Research scholar, Dept. of EEE, University of Engineering and technology Peshawar, KP, Pakistan \\ Received: 14 March, Revised: 19 March, Accepted: 20 March
}

\begin{abstract}
Power system stable operation requires, generating power of the system equivalent to the sum of all losses and affiliated load. Therefore, excess of load needs to be shed especially in islanding mode because generators are running at rated capacity. Different factors e.g. over current, low voltage level and frequency affect system performance but among them constant frequency is imperative for the steady functioning of power system because frequency is constant at every voltage level and hence, a dependable and reliable parameter to show imbalance situation. Additionally, active power deficit. System frequency is very sensitive to disturbance specially in islanding mode and is severely affected by the power imbalance between power generation and load which leads to overload or power generation loss. To shed excess load, U.F.L.S. (Under Frequency Load Shedding Scheme) is implemented. This research here presents Under Frequency Load Shedding Scheme for islanded distribution network. This proposed adaptive U.F.L.S scheme use swing equation to find power imbalance. It takes into consideration ROCOF (rate of change of frequency) and power imbalance and based on this data load is shed in single step which is better than cascading as other traditional U.F.L.S implements cascading steps and the response time to any magnitude of disturbance is also better than others. The adaptive U.F.L.S scheme is tested in Simscape Power System and Simulink (Software Packages in MATLAB) and the results shows that it stabilized the frequency thus stabilizing the system by shedding the right amount of imbalance load.
\end{abstract}

Keywords - Load Shedding, ROCOF (Rate Change of Frequency), Adaptive U.F.L.S, Islanding and Overload.

\section{INTRODUCTION}

Electrical power system stable operation requires, generating power of the system equivalent to the sum of all losses and affiliated load. Different factors e.g. over current, low voltage level, under \& over frequency affects the stability of power system. Extreme example is complete blackout/collapse of the system. Large generators are considered economical to operate. however, in the event of instability huge number of consumers are affected. In any particular system, instability is a constant threat to the system. Usually in power system, the power house is at a very large distance from the load and there is a chance that the whole system collapse if the power station trips and therefore, needs real time system measurement parameters to change power generation accordingly so that the system remains stable.

While it is not completely possible to eliminate faults and failures from a power system however, it can be minimized and if not minimized and controlled properly, it can lead to severe blackouts and even system collapse. As a result, consumers will be affected and the utility in financial terms. Hence, it is imperative to design a system to cope with abrupt/unforeseen faults and continue to function with minimal disturbance in delivering of power to the consumer.

Stable frequency is imperative for the steady functioning of power system. Frequency is constant at every voltage level and hence, a dependable and reliable parameter to indicate imbalance situation. In electrical power system, frequency shows us the active power deficit. To sustain the frequency of electrical power system, mechanical-power input to the prime movers of alternators must be equivalent to the aggregate of all affiliated load and associated power losses of the system. Equilibrium/stability is disturbed when input or output are changed. Mathematically, a stable state is:

Power Generation $=$ Connected load + Associated losses .

The unexpected loss of transmission line, transformer, and alternator create an imbalance condition in which load will become more than the power generation, leading to frequency decline. The usage of Distributed Generation (DG) is going to expand with each passing day. Thus, islanding operation at distribution level will grow. It's quite a possibility that in future the entire region (national grid) is partitioned in to a number of islanded region and operate each and every region individually. Islanded region needs an effective and efficient protection scheme just like a national grid (inter connected system), For stability reasons, the power generation and affiliated load of an islanded region must be well-balanced. The most essential protection strategy for islanded distributed network is under frequency load-shedding scheme. Additionally, the reliability of islanded area/region can be enhanced by constantly supplying electrical power from Distributed Generation. 


\section{DESCRIPTION}

A. Objective

- Nearly constant frequency for stable operation of an islanded region

- Stability in terms of power system protection, especially generators and turbines.

\section{B. Islanding}

An area or a region with one or two generating units serving local load of that area is known as islanded region. This local generation is known as DG. Main power source in this region is DG. Possibly it can be solar or wind or small hydro. The owner of DG earns more by selling power apart from having continuous supply and with time, power quality enhances because of the competition. All power utilities presently, turn off power when distribution system detects islanding. In accordance to IEEE-1547-2003 established standard, in case islanding detected, power must be cut off within 2 secs and this is also started in IEC 61727 [1]. In Denmark it is avoided to have maximum of $25 \mathrm{MW}$ utilization of generations units while islanding [2]. Power service providers/Utilities avoid this situation because;

- It possibly puts line workers life in danger if DG powers islanded region. if not properly grounded, un-faulted phase lines have very high voltage during earth faults [3].

- For protection reasons, the DG's power failure assistance probably not enough for reliable functioning as a result continued fault current [4].

- Most important point, the power utility companies avoid islanding because they are of the opinion that DG probably not capable to keep frequency and voltage inside required range during islanded mode [4].

- For reconnecting transmission and distribution system, most of the power utility companies utilize an instant recloser-breaker which results in out-of-phase closing. Thus, creating currents and mechanical torques which may damage the prime movers/generating units [5].

- At distribution level the usage of DG has increased sharply. It is inefficient to use traditional methods to turn off DG. In islanding mode, among the power providers the competition is growing, enhancing the reliability and quality [6].

\section{U.F.L.S schemes}

- Traditional/Conventional UFLS Scheme; Load first block is shed at $49.5 \mathrm{~Hz}$ as most power utilities exercise 49.5 as the 1 st limitation/threshold. A particular magnitude of load is removed at a number of determined frequency thresholds between 49.5 $47.5 \mathrm{~Hz}$. Between two thresholds a proper amount of pause is necessary to examine the effect of loadshedding on frequency. Also, important to check if successive shedding sheds large amount of load without checking, frequency may overshoot its normal value. Frequency declines fast if disturbance is huge. Therefore, it may not be enough to shed just specified load compared to the frequency fast decline rate. This type of scheme has several disadvantages; one such is - load that is shed is pre-determined without taking into account the amount of power deficiency and intensity of turbulence. This scheme /strategy is ordinary \& complex relay systems is not necessary. Frequency threshold and value of load for shedding is pre specified \& fed to relay on the basis of experience [7]. If frequency continues to drop after first threshold, the process of load shedding continues at each threshold until it reaches its normal value.

- Semi adaptive UFLS Scheme; This type of scheme and traditional U.F.L.S are somewhat different. In this type of scheme, the first block of load is shed by determining ROCOF (rate of change of frequency). ROCOF may not always be the same because it relies on the value of load varied. So, for the load first block to shed, three or four different levels of frequency threshold is specified along with amount of load for each and whichever frequency threshold ROCOF matches its corresponding load is shed. For instance, ROCOF is $-0.40 \mathrm{~Hz} / \mathrm{sec}$. then predefined load of $110 \mathrm{MW}$ is shed \& if $-0.90 \mathrm{~Hz} / \mathrm{sec}$. then $170 \mathrm{MW}$ of pre-determined load-shedding. It only checks the speed of frequency variation; speedier the variation, greater the load-shedding. So, this schema only relies on ROCOF but just for the first step and after that it follows the same traditional U.F.L.S scheme [5].

- Adaptive UFLS Scheme; Using swing equation, this adaptive/dynamic U.F.L.S schema shed varied value of load every step by determining the magnitude of disturbance. When the disturbance is very high, a significant amount of load is disconnected but when less then small volume of load is shed. Therefore, the amount/volume of load to be disconnected is not predefined or fixed and is dependent on the amount of load as well frequency Due to this, this adaptive scheme stabilizes frequency faster than the other two schemes previously mentioned. Moreover, rather than a stepping/cascading scheme, a single step scheme produces better response of frequency Therefore, this scheme is preferred over other two schemes [8].

$\Delta P=2 * H *\left(\frac{d f}{d t}\right)$

Wherein;

$\mathrm{df} / \mathrm{dt}$ - ROCOF (Rate of change of Frequency)

$\Delta \mathrm{P}$ - Power Deficiency

$\mathrm{H}$ - Inertia-constant (in seconds)

Definition of $\mathrm{H}$ as the ratio of rotating components of alternator's moment of inertia to a unit capacity. Bigger values of $\mathrm{H}$, slower the frequency fall for a given overload. Old generators like the water wheel units had $\mathrm{H}$ as big as 10 secs but the modern turbine units have $\mathrm{H}$ value of $2-3$ secs. because the 
tendency is having smaller rotor masses resulting bigger output.

\section{PROPOSED WORK IMPLEMENTATION AND RESULTS}

The problem of maintaining Frequency in desired range is solved by dividing into three sections

- Mechanical torque control

- Calculating imbalance power

- Providing an extra power when load increases

\section{A. Mechanical Torque Control}

Islanding system with DG distribution network is first run without mechanical torque control to show the adverse effects of not having mechanical torque. If load is shed then frequency will rise. Also, the rotor speed which may run so faster that may damage the alternator. That's why system with mechanical torque is preferred. After this, mechanical torque control is introduced into the system. Once there, it can detect the frequency rise or depress and changes the mechanical shaft input accordingly to maintain frequency in desired range. Generator ratings;

- Generator of 4MVA

- $\quad$ Output $(\mathrm{O} / \mathrm{P})$ power $=3200.0 \mathrm{~kW}(0.8$ power-factor $)$

- $\quad$ Frequency $(\mathrm{f})=50.0 \mathrm{~Hz}$

- $\quad$ Total no. of poles $(\mathrm{P})=2.0$

- $\quad$ Speed $=3000.0 \mathrm{rpm}$

- Initial Load $=3200.0 \mathrm{KW}$

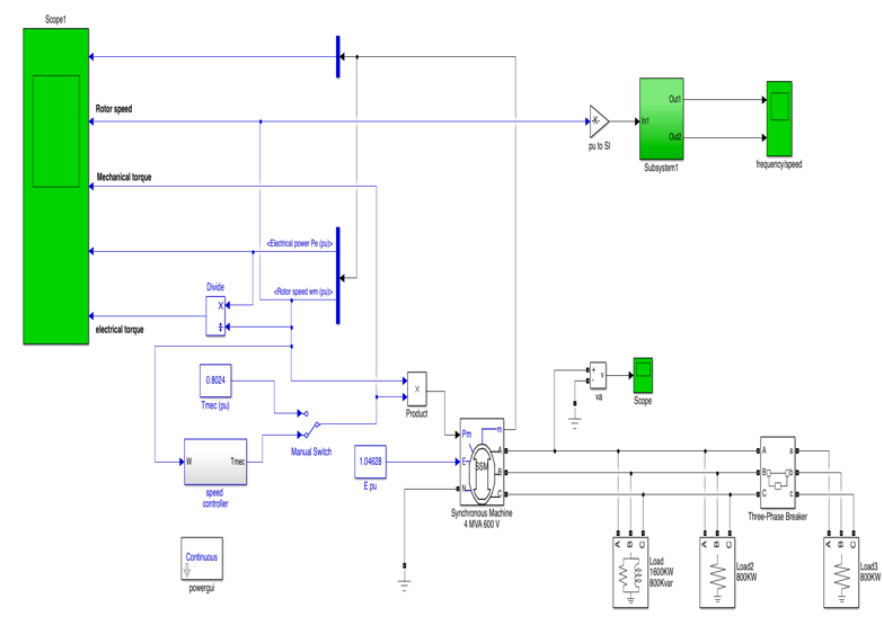

Figure 1. Schematic of system with $\&$ without mechanical torque control

The initial load is divided into three blocks i.e. $1600 \mathrm{KW} \&$ two $800 \mathrm{KW}$ blocks each. Schematics shown in figure 1 . At 0.2 seconds, load of $800 \mathrm{KW}$ is shed from the system and after the simulations, graphs are taken from both to show the difference that how important it is to maintain the frequency. Figure 2 shows frequency having no mechanical torque control and figure 3 shows frequency having mechanical torque and figure 4 show controlled mechanical torque response.

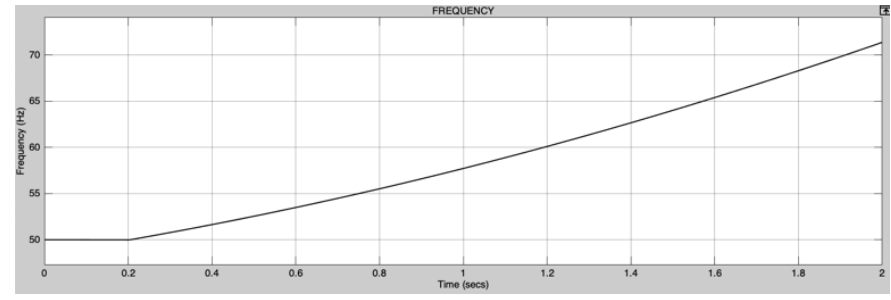

Figure 2. Frequency without mechanical torque control

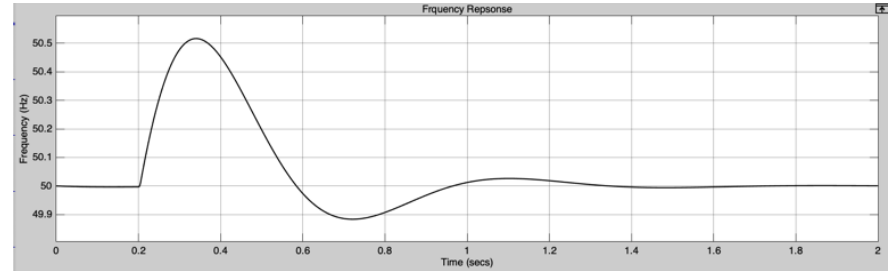

Figure 3. Frequency with mechanical torque control

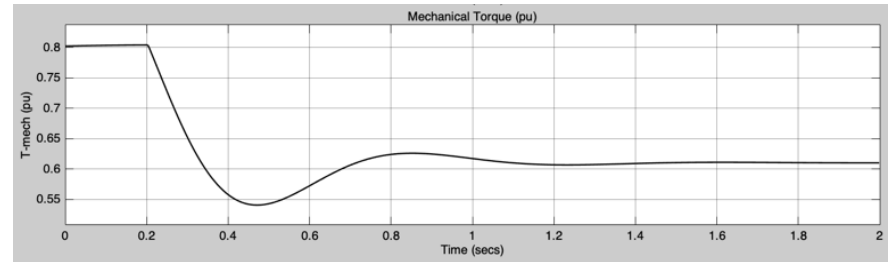

Figure 4. Controlled mechanical torque response

\section{B. Calculating an imbalance power}

To deal with system that is under frequency depress or on frequency rise, it is necessary to shed right amount of load. To maintain stable frequency in desired under load and overload both conditions are considered. Generator ratings:

- $125 \mathrm{kVA}$ Generator

- $\mathrm{O} / \mathrm{P}$ Power $=100.0 \mathrm{~kW}(0.8$ power-factor $)$

- $\quad$ Frequency $(\mathrm{f})=50.0 \mathrm{~Hz}$

- $\quad$ Total no. of Poles $(\mathrm{P})=2.0$

- $\quad$ Speed $=3000.0 \mathrm{rpm}$

- $\quad$ Initial Load $=100.0 \mathrm{~kW}$

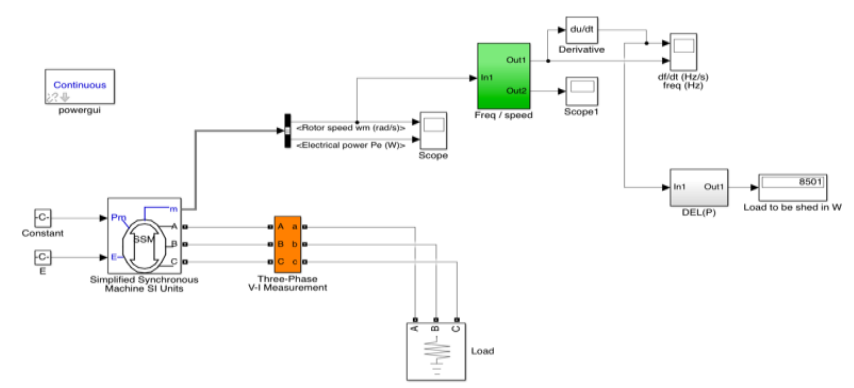

Figure 5. Calculating an imbalance power of system

Schematics for both conditions are designed accordingly, shown in figure 5. Firstly, an overload conditioned is implemented which calculates the excess load and then the 
system sheds that load, then an under-load condition is implemented which again calculates the amount of load necessary to be added to the system and after the calculation, adds to the system right way. Graphs for both scenarios are taken to show the frequency depress and stabilize and again frequency rise.

At first the entire load of $100 \mathrm{~kW}$ is on generator. It is then incremented from 100 to $108.5 \mathrm{~kW}$, that additional load leading to frequency depreciation as shown in figure 6. Swing-equation is applied to find the power difference between power produced and power demand/load. Frequency normalizes after loadshedding of $8.5 \mathrm{KW}$ load \& comes back to rated value as shown figure 7. Also, the power station is tested in a condition when the power generation is more than power demand (load) as shown in figure 8. $-9400 \mathrm{~W}$ is shown as an imbalance power. The negative sign shows that this much of a load is less than power generated or need to be added to the system or the mechanical power input need to be lowered in accordance with the load on system. Table 1 summarize imbalance power situatuin.

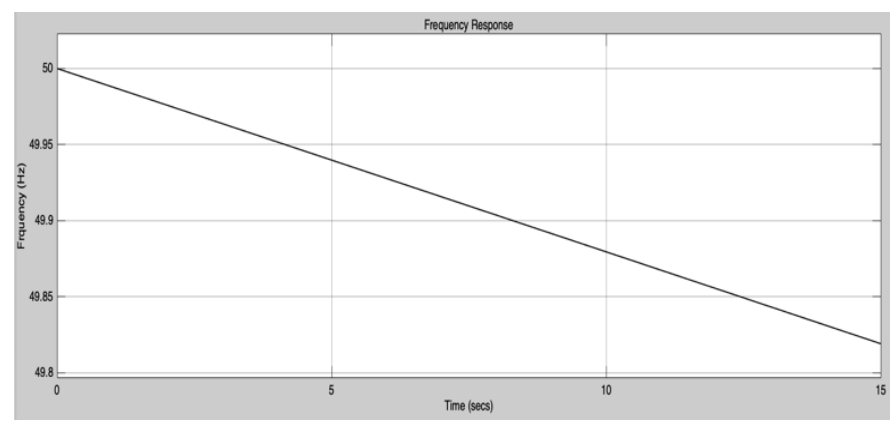

Figure 6. Frequency before load shedding

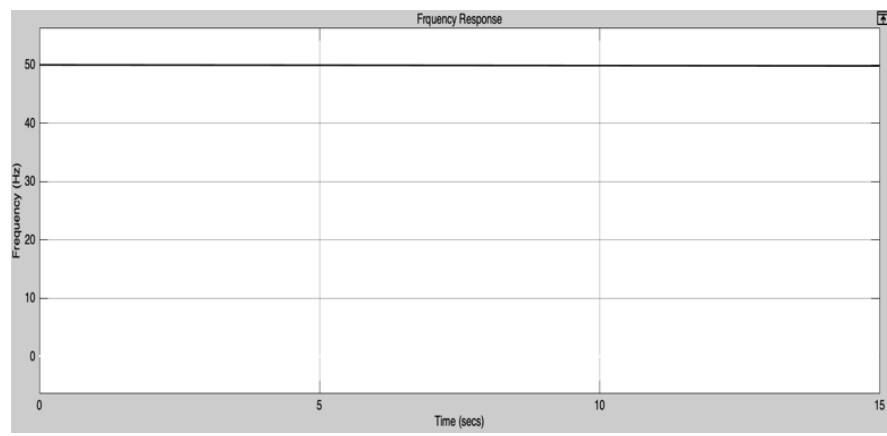

Figure 7. Frequency after load shedding

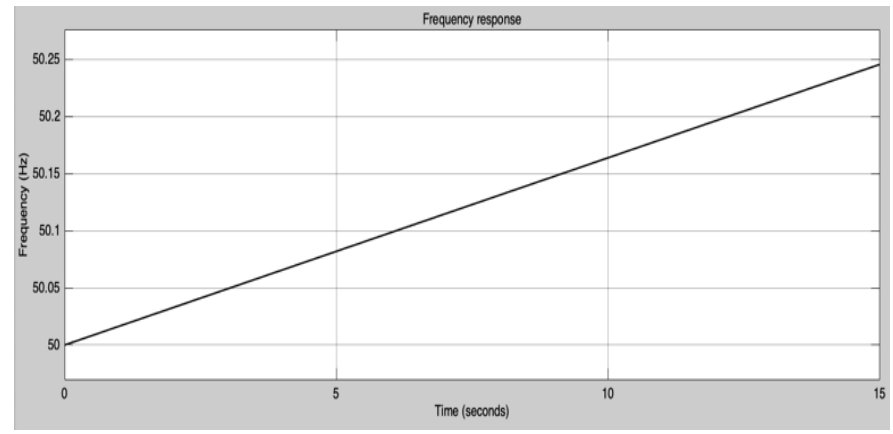

Figure 8. Frequency at small load
TABLE I. TO DETERMINE AN IMBALANCE POWER

\begin{tabular}{|c|c|c|}
\hline $\begin{array}{c}\text { Load } \\
(\mathrm{KW})\end{array}$ & Frequency (f)(Hz) & $\begin{array}{c}\Delta \mathrm{P} \text { (power } \\
\text { imbalance) }(\mathrm{W})\end{array}$ \\
\hline $100.0 \mathrm{KW}$ & $50 \mathrm{~Hz}$ & 0.0 \\
\hline 108.50 & Fall from $50 \mathrm{~Hz}$ to \\
$\mathrm{KW}$ & $49.8 \mathrm{~Hz}$ & $8500 \mathrm{~W}$ \\
\hline $91.0 \mathrm{KW}$ & Rose from $50 \mathrm{~Hz}$ to & $-9400.0 \mathrm{~W}$ \\
& $50.25 \mathrm{~Hz}$ & \\
\hline
\end{tabular}

C. Automatically adding a generator with increase in load Generator power rating:

- $500 \mathrm{kVA}$ generator each (three generators)

- $\quad$ Total Power Output $=1500.0 \mathrm{~kW}$

- $\quad$ Frequency (f) $=50 \mathrm{~Hz}$

- $\quad$ No. of Poles $(\mathrm{P})=2.0$

- $\quad$ Speed $=3000.0 \mathrm{rpm}$

- Initial Load $=1000.0 \mathrm{~kW}$

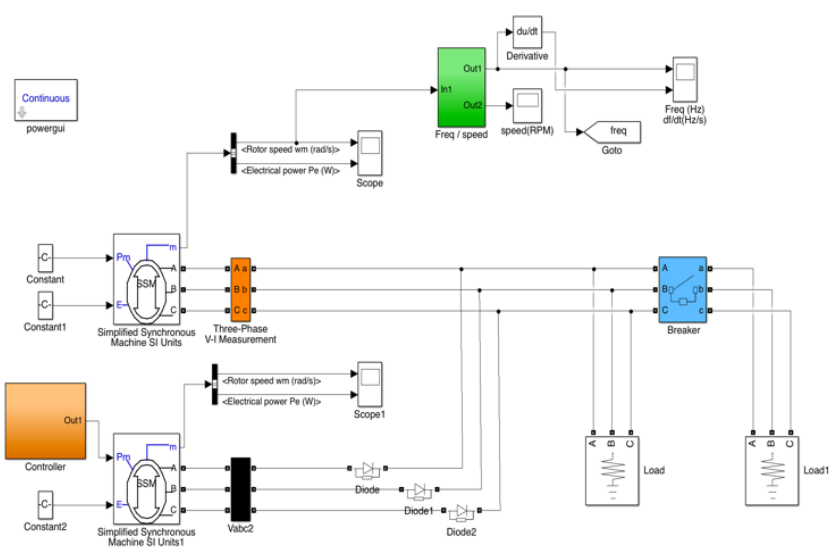

Figure 9. Automatically adding a generator

At first load of $1 \mathrm{MW}$ is attached as shown figure 9. only one generator is on standby while the other is contributing to generation. Circuit-breaker closes at $\mathrm{t}=4 \mathrm{sec}$; incrementing the net load to $1500 \mathrm{~kW}$ from $1000 \mathrm{~kW}$. To maintain the frequency at rated value/constant a controller links the second standby generator to system. Second generator starts up when it receives a signal as mech-power input from controller which determines the power difference btw power demand \& power generators capacity.

Figure 10 shows frequency response when load is increases and then a standby generator is added to the system to stabilize the frequency of the sytem. 


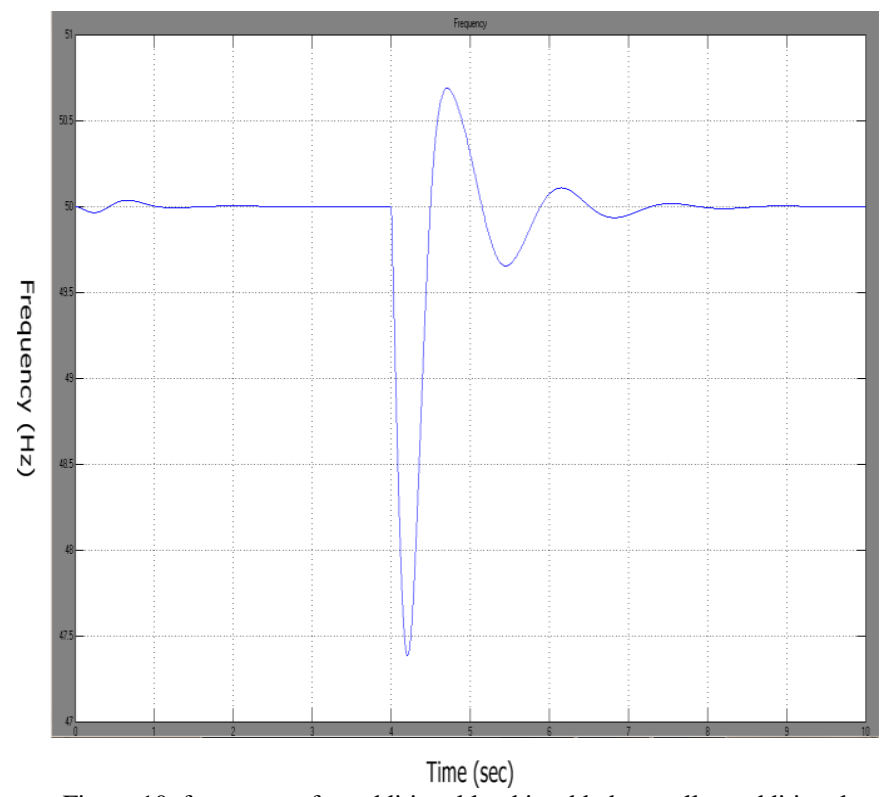

Figure 10. frequency after additional load is added as well an additional generator

\section{CONCUSLION}

A traditional load shedding scheme is depicted in table 2, in which percentage of load is shed according to frequency threshold are presented. Traditional load shedding scheme does not take into account the power deficit and magnitude of disturbance, value of load to disconnect is pre-determined. An incident of huge disruption, frequency fall is very sudden and disengaging pre-determined load may not be of great use to stabilize frequency from decline. The adaptive UFLS scheme discussed in this research consider the level of disturbance \& sheds load depending upon the frequency \& the rate of change of frequency.

TABLE II. A TRADITIONAL UFLS SCHEME

\begin{tabular}{|c|c|c|c|}
\hline Threshold frequency & $49.50 \mathrm{~Hz}$ & $49.00 \mathrm{~Hz}$ & $48.50 \mathrm{~Hz}$ \\
\hline $\begin{array}{c}\text { Load that is to be shed in } \\
\text { percent }\end{array}$ & $40 \%$ & $30 \%$ & $30 \%$ \\
\hline
\end{tabular}

The method implemented in this research is very advantageous because not only take care of the system, when there is an overload, but also when the generation is greater than the load (in this situation frequency rises than the nominal value, $50 \mathrm{~Hz}$ which is also an unstable and unwanted condition). Moreover, load is shed in just one stepping as compared to other traditional schemes and as a result of one stepping, response time to stabilize frequency is less compared to other traditional schemes.
TABLE III.

COMPARISON BTW STATE ESTIMATION VS ADAPTIVE UFLS

\begin{tabular}{|c|c|c|c|}
\hline \multicolumn{3}{|c|}{ Power Imbalance Calculation Comparison } \\
\hline $\begin{array}{c}\text { Method presented in a Paper } \\
\text { [9], ULFS \& state } \\
\text { estimation scheme }\end{array}$ & \multicolumn{2}{|c|}{$\begin{array}{c}\text { Method presented in this } \\
\text { research }\end{array}$} \\
\hline $\begin{array}{c}\text { Power } \\
\text { imbalance } \\
(\mathrm{KW})\end{array}$ & $\begin{array}{c}\text { Load shed } \\
(\mathrm{KW})\end{array}$ & $\begin{array}{c}\text { Power } \\
\text { imbalance } \\
(\mathrm{KW})\end{array}$ & $\begin{array}{c}\text { Load shed } \\
(\mathrm{KW})\end{array}$ \\
\hline 300 & 113 & 8.5 & 8.5 \\
\hline 450 & 284 & -9.4 & -9.4 \\
\hline
\end{tabular}

From the above table, it is obvious that this proposed adaptive UFLS schemes works accurately and is better. Furthermore, the response time is excellent. Its response time from cascading UFLS is much better.

It is a common knowledge that the general grid is much bigger than the islanded region and hence it has much bigger system inertia as well spinning reserve, therefore during frequency depress situation the general grid response time will be slower as compared to islanded region.

\section{A. Future Work}

In this research only the simulations are carried out to implement the proposed methods to maintain frequency in desired range however its scope can be further extended by;

- Protection of reverse power flow from islanding region to the main grid.

- $\quad$ Preferential load shedding scheme to shed low priority load first and high priority load last.

- Fine tuning this existing scheme to improve its response time.

- Economical aspect of the work done.

- Hardware based implementation.

\section{REFERENCES}

[1] Photovoltaic (PV) systems Characteristics of the utility interface, IEC 61727 Standard, December 2004.

[2] K. Christensen, "Technical Regulation for Thermal Power Station Units of 1.5 MW and higher," Energinet.dk, Fredericia, Denmark, Regulation for grid connection TF 3.2.3, 2008.

[3] P. P. Barker and R. W. de Mello, "Determining the Impact of Distributed Generation on Power Systems 1 - Radial Distributed Systems," IEEE Power Engineering Society Summer Meeting, vol. 3, pp. 1645-1656, 2000.

[4] S. P. Chowdhury, S. Chowdhury, P. A. Crossley, and C. T. Gaunt, "UK scenario of islanded operation of active distribution networks with renewable distributed generators," International Journal of Electrical Power \& Energy Systems 33, vol. 34, no. 12, pp. 2585-2591, 2011.

[5] R. A. Walling and N. W. Miller, "Distributed Generation Islanding Implications on Power System Dynamic Performance," IEEE Power Engineering Society Summer Meeting, vol.1, pp. 92-96, 2002. 
[6] IEEE Standard for Interconnecting Distributed Resources into Electric Power Systems, IEEE Standard 1547TM, 2003.

[7] Md. Quamrul, Ahsan, A. H. Chowdhury, S. S. Nawaz, I. H. Bhuyan, M A. Haque, and H. Rahman, "Technique to Develop Auto Load Shedding and Islanding Scheme to Prevent Power System Blackout," IEEE Transactions on Power Systems, pp. 198-205, 2012.

[8] X. Cao, I. Abdulhadi, C. Booth and G. Burt, "Defining the Role of Wide Area Adaptive Protection in Future Networks," IEEE international Universities Power Engineering Conference (UPEC), pp.1-6, 2012.

[9] J. A. Laghari, H. Mokhlis, A. B. Halim, A. Bakar, M. Karimi and A. Shahriari, "A New Under-Frequency Load Shedding Scheme for Islanded Distribution Network" IEEE Innovative Smart Grid Technologies (ISGT), pp. 1-6, 2013.

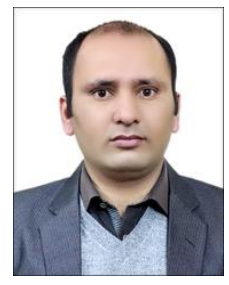

Nauman Ahmed (Peshawar, DOB 07/05/1990) received the B.Sc degree from the Department of Electrical and Electronics, University of Engineering and Technology Peshawar, Khyber Pakhtunkhwa, Pakistan, in 2014. He is doing his Master from the UET Peshawar with specialization in Electrical Power. His research interests are Under Frequency Load Shedding Scheme for Islanding Distribution Network. His email address is nauman236@gmail.com.

Professor Dr. Muhammad Naeem Arbab is a Professor in University of Engineering and Technology Peshawar in Electrical Department. He got his Ph.D. from UK and is an author of two engineering books i.e., High Voltage Engineering and Electrical Power Generation and published more than 25 research papers. His email address is mnarbab@gmail.com.

Hammad Israil Awan (Peshawar, DOB 18/12/1988) Received the B.Sc degree from the Department of Electrical \& Electronics, University of Engineering \& Technology Peshawar, Khyber Pakhtunkhwa, Pakistan, in 2014. He is doing his Master from UET Peshawar with Specialization in Electrical Power. His research interests are design \& fabrication of novel power point tracking (MPPT) based charged controller for enhanced electrical performance. His email address is hammy_awan@hotmail.com.

Shehla Noor (Peshawar, DOB 10/02/1994) received the B.Sc degree from the Department of Electrical \& Electronics, University of Engineering \& Technology Peshawar, Khyber Pakhtunkhwa, Pakistan, in 2016. She is doing her Master from UET Peshawar with Specialization in Energy System Engineering. Her research interests are Analyzing Cost optimization techniques for electrification of grid connected and islanded micro grid. Her email address is shehlanoor231@yahoo.com. 